\title{
Microstructures and Electrochemical Behavior of Ti-Mo Alloys for Biomaterials
}

\author{
Back-Sub Sung, ${ }^{1}$ Tae-Eon Park, ${ }^{2}$ and Young-Hoon Yun ${ }^{3}$ \\ ${ }^{1}$ Department of Mechanical Engineering, Chosun University, Gwangju 501-759, Republic of Korea \\ ${ }^{2}$ Ecotechkorea Co. Ltd., Jeonnam Advanced Ceramics Center, Jeonnam 530-370, Republic of Korea \\ ${ }^{3}$ Department of Hydrogen \& Fuel Cell Technology, Dongshin University, Jeonnam 520-714, Republic of Korea \\ Correspondence should be addressed to Young-Hoon Yun; yunemail@naver.com
}

Received 26 December 2014; Revised 24 February 2015; Accepted 26 February 2015

Academic Editor: Hongchao Kou

Copyright (C) 2015 Back-Sub Sung et al. This is an open access article distributed under the Creative Commons Attribution License, which permits unrestricted use, distribution, and reproduction in any medium, provided the original work is properly cited.

The Ti alloy with $7 \mathrm{wt} \%$ Mo revealed a microstructure that contained only the orthorhombic $\alpha^{\prime \prime}$ phase of a fine acicular martensitic structure. The corrosion resistance of the Ti-Mo alloys increased as the Mo content increased. Based on the results obtained from the polarization curve and electrochemical impedance, the Ti-Mo alloys were shown to be corrosion resistant because of the passive films formed on their surfaces. No ion release was detected in SBF (simulated body fluid) solution, while Ti ions were released in $0.1 \%$ lactic acid ranging from 0.05 to $0.12 \mu \mathrm{g} / \mathrm{mL}$ for the Ti-Mo alloys. In vitro tests showed that MC3T3-E1 cell proliferation on Ti-7 wt\% Mo alloy was rather active compared to other Ti-Mo alloys and commercial-grade pure Ti.

\section{Introduction}

Both commercial-grade pure titanium (CP Ti) and the $\mathrm{Ti}$ $6 \mathrm{Al}-4 \mathrm{~V}$ alloy have been widely used for orthopedic and dental implant materials because of their excellent combination of biocompatibility, corrosion resistance, and beneficial mechanical properties $[1,2]$. However, an alternative to the Ti-6Al-4V alloy that is currently being utilized should be developed because the release of $\mathrm{Al}$ and $\mathrm{V}$ ions into the human body causes long-term health problems [3-5]. Another disadvantage of this material is the mismatch of Young's modulus between the Ti implant (100-120 GPa) and bone (10-30 GPa), which is unfavorable for bone healing and remodeling $[6,7]$. To address these problems and further improve the biological and mechanical properties of $\mathrm{Ti}$ alloys, many $\mathrm{Ti}$ alloys have been developed for biomedical applications [6-8]. These efforts have focused on the development of novel titanium alloys using nontoxic elements. For this purpose, $\beta$-type titanium alloys composed of nontoxic elements, such as niobium ( $\mathrm{Nb})$, tantalum (Ta), zirconium $(\mathrm{Zr})$, molybdenum (Mo), and tin (Sn), with lower moduli of elasticity and greater strengths should be developed [7-10]. In recent studies, binary Ti alloys employed as biomaterials have been investigated, with emphasis on their microstructure and mechanical properties [10-13].

In the present study, the elastic modulus, corrosion behavior, electrochemical properties, and microstructures of homogenization-treated binary Ti-Mo alloys with Mo contents ranging from 3 to $15 \mathrm{wt} \%$ were investigated.

\section{Experimental}

The elastic modulus, corrosion resistance, and biocompatibility of binary Ti-Mo alloy specimens with Mo contents of $3,7,10$, and $15 \mathrm{wt} \%$ were investigated. Ingots of the studied alloys, consisting of commercially pure sponge titanium (99.5\%, grade 4) and pellet Mo (99.95\%), were melted under an argon atmosphere using a nonconsumable tungsten electrode. These alloys were melted 10 times with inversion of the liquid metal to obtain homogeneous structures. This process was followed by homogenization treatments that were performed at $1000^{\circ} \mathrm{C}$ under an Ar atmosphere for $24 \mathrm{hrs}$ and then quenched in water. The chemical compositions of the studied Ti-Mo alloys, as determined through wet chemical and gas analysis, are summarized in Table 1; this 

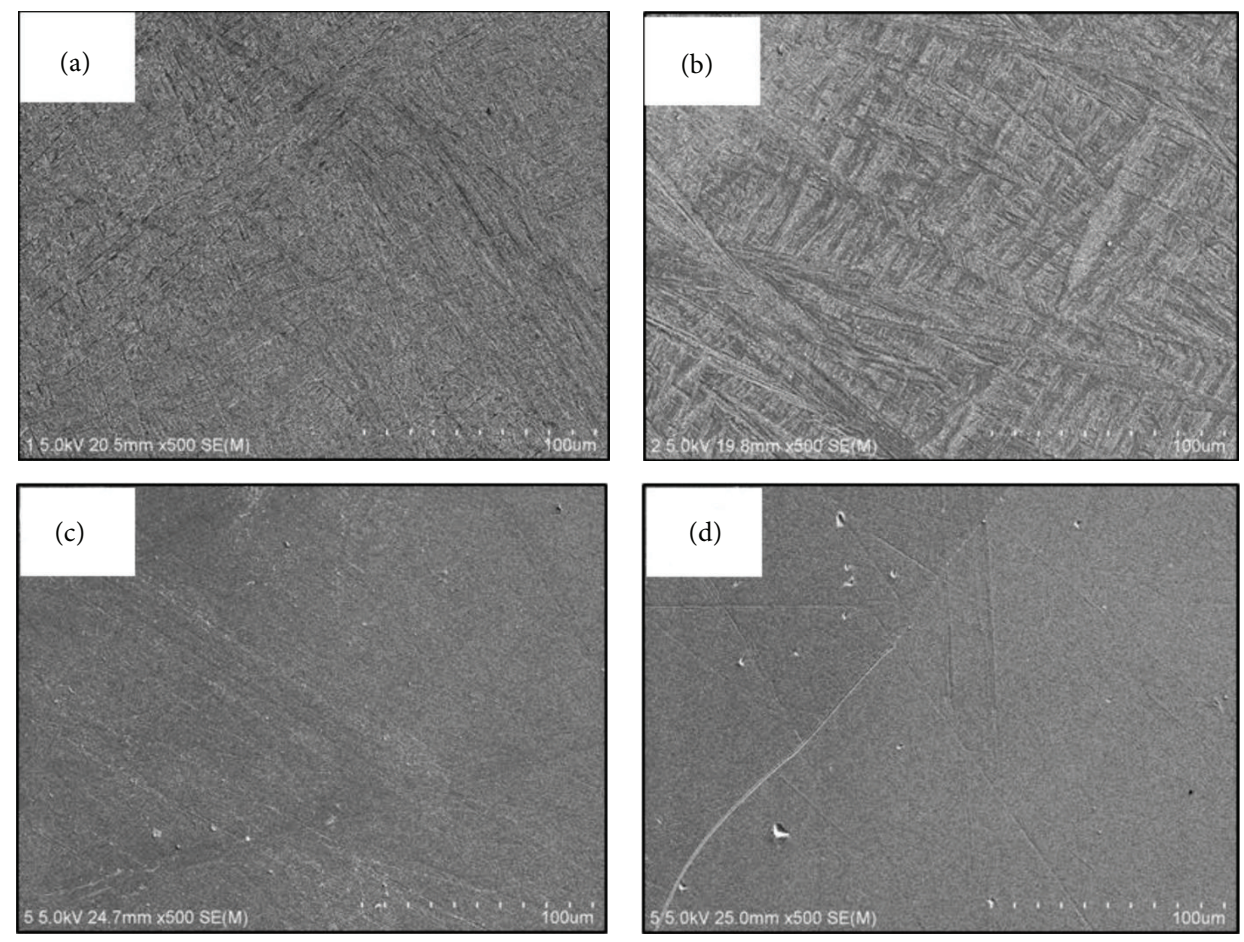

Figure 1: SEM micrographs showing the microstructures of the Ti-xMo alloys: (a) Ti-3Mo, (b) Ti-7Mo, (c) Ti-10Mo, and (d) Ti-15Mo.

TABLE 1: Chemical compositions of the studied Ti-Mo alloys.

\begin{tabular}{lccc}
\hline Alloy code & Mo $(w t \%)$ & O (wt $\%)$ & Ti $(w t \%)$ \\
\hline Ti-3Mo & 2.9 & 0.064 & Balance \\
Ti-7Mo & 6.8 & 0.035 & Balance \\
Ti-10Mo & 9.9 & 0.048 & Balance \\
Ti-15Mo & 14.6 & 0.088 & Balance \\
\hline
\end{tabular}

table shows that the actual chemical composition of each designed alloy was similar to its nominal composition.

Young's modulus were measured using a dynamic ultramicrohardness tester (DUHW 201S, Shimadzu Co., Japan). The apparent elastic modulus of each sample, $E^{*}$, was calculated using the load-displacement curve and the standard Hertzian contact theory [14]:

$$
E^{*}=\left(\frac{9}{16}\right)^{1 / 2} P h^{-3 / 2} R^{-1 / 2},
$$

where $h$ is the depth of elastic penetration of the indenter, $P$ is the load, and $R$ is the indenter radius. The true modulus of the sample, Es, can be calculated from the apparent modulus by accounting for the elastic properties of the indenter.

The microstructural morphologies of the homogenization-treated Ti-Mo alloys were observed using a fieldemission scanning electron microscope (FE-SEM, Hitachi S4800, Japan). Crystal phases were identified using an X-ray diffractometer (X'Pert MPD PW3040, Philips, Netherlands).

Anodic polarization tests and an ion-release test in a simulated body fluid (SBF) were conducted. The electrodes for the anodic polarization tests were prepared via cold mounting with epoxy resin followed by mechanical polishing with emery paper of up to 2000 grit. The SBF solution, which was composed of $\mathrm{NaCl}(8 \mathrm{~g}), \mathrm{KCl}(0.22 \mathrm{~g})$, $\mathrm{Ka}_{2} \mathrm{HPO}_{4} \cdot 12 \mathrm{H}_{2} \mathrm{O}(0.15 \mathrm{~g}), \mathrm{NaSO}_{4}(0.08 \mathrm{~g}), \mathrm{NaHCO}_{3}(0.35 \mathrm{~g})$, and $\mathrm{CaCl}_{2}(0.27 \mathrm{~g})$, was used as an electrolyte solution at a $\mathrm{pH}$ of 7.4 and a temperature of $37^{\circ} \mathrm{C}$. Potentiodynamic polarization scans were performed at a scan rate of $1 \mathrm{mV} / \mathrm{s}$ in the range from -1500 to $1500 \mathrm{mV} / \mathrm{SCE}$. Immersion tests to assess the metal-ion release were conducted in the SBF solution ( $\mathrm{pH} \mathrm{7.4)}$ and in $0.1 \%$ lactic acid $\left(\mathrm{pH} \mathrm{3.4)}\right.$ at $37^{\circ} \mathrm{C}$. Each solution was collected every 5 days for 30 days. The concentrations (average values of three times) of metal ions that were released into the solutions were analyzed up to $10 \mathrm{ppb}(0.01 \mu \mathrm{g} / \mathrm{mL})$ via inductively coupled plasma-mass spectrometry (ICP-MS, JY 70Plus, Longjumeau, France).

In order to evaluate cytocompatibility of the alloys, MC3T3-E1 cells (RCB 1126, an osteoblast-like cell line from C57BL/ 6 mouse calvaria) were cultured on Ti-Mo alloy plates in DMEM-HG and in $5 \% \mathrm{CO}_{2}$ at $37^{\circ} \mathrm{C}$ with a cell seeding density $1.5 \times 10^{4}$ cells/well. The cell viability was measured with a 3-(4,5-dimethylthiazol-2yl)-2,5-diphenyl tetrazolium bromide (MTT) assay and was carried out after 1 and 3 days of culturing using an ELISA plate reader (precision microplate reader, Molecular Devices, Sunnyvale, CA, USA).

\section{Results and Discussion}

3.1. Microstructures and Elastic Modulus of Ti-Mo Alloys. Figure 1 shows the microstructures of the Ti alloys with 3, 7, 10 , and $15 \mathrm{wt} \%$ Mo after heat treatment for homogenization. The specimens of the Ti-Mo alloys with 3 and 7 wt\% Mo exhibited a fine acicular, martensitic structure of the $\alpha^{\prime \prime}$ 


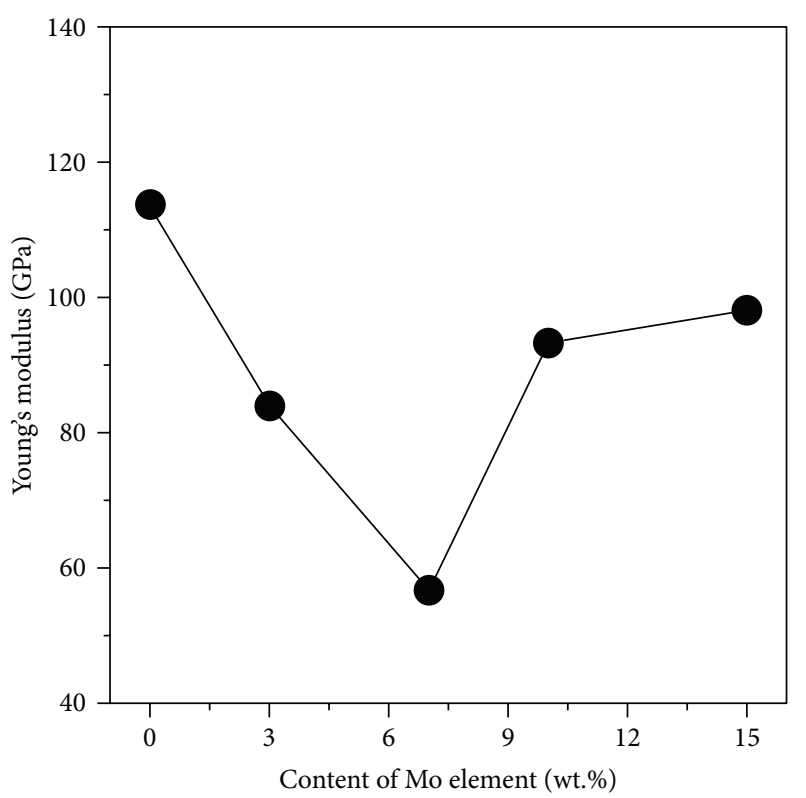

FIGURE 2: Elastic moduli of the Ti-xMo alloys.

phase in their surface microstructures [11]. When the Mo content increased, the fine acicular patterns in the Ti-Mo alloys disappeared. These results confirmed that the Mo content influences the formation of the martensite phase and effectively suppresses grain-growth behavior $[13,14]$.

Figure 2 presents the elastic modulus of the homogenization-treated Ti-Mo alloys with respect to the varying Mo contents. The elastic modulus of the Ti-Mo alloys decreased with the addition of Mo, although the actual value of the modulus fluctuated with different Mo contents. The elastic modulus decreased as the Mo content increased up to $7 \mathrm{wt} \%$ but then increased as the Mo content was further increased to $15 \mathrm{wt} \%$. It is interesting to note that the elastic modulus of Ti-7Mo was very low (i.e., approximately $55 \mathrm{GPa}$ ); this result is in good agreement with that of Ho et al. [15].

Figure 3 shows the X-ray diffraction patterns of the TiMo alloys. When a Mo content of $3 \mathrm{wt} \%$ was added, the homogenized alloy exhibited peaks corresponding to the hexagonal $\alpha^{\prime}$ and orthorhombic $\alpha^{\prime \prime}$ phases. It was found that, in certain alloys (i.e., Ti-Mo, Ti-Nb, Ti-Ta, etc.), the hexagonal $\alpha^{\prime}$ phase distorts and transforms into an orthorhombic $\alpha^{\prime \prime}$ phase [16]. The Ti-7 wt\% Mo showed just the martensitic $\alpha^{\prime \prime}$ phase. When the Mo content increased to $10 \mathrm{wt} \%$ or higher, only the $\beta$ phase was observed in the XRD patterns. The retention of the $\beta$ phase at higher Mo contents is consistent with the results of Ho et al. [15].

3.2. Corrosion Resistance of Ti-Mo Alloys. Figure 4 presents the potentiodynamic polarization curves for the Ti-Mo alloys compared with $\mathrm{CP} \mathrm{Ti}$ as tested in the $\mathrm{SBF}$ solution at $37^{\circ} \mathrm{C}$. Some shift in the corrosion potential $\left(E_{\text {corr }}\right)$ and a remarkable reduction in the corrosion current densities $\left(I_{\text {corr }}\right)$ are evident, which indicate enhanced corrosion resistance. The differences in corrosion potential among the alloys may be attributable to tiny differences in surface conditions [17],

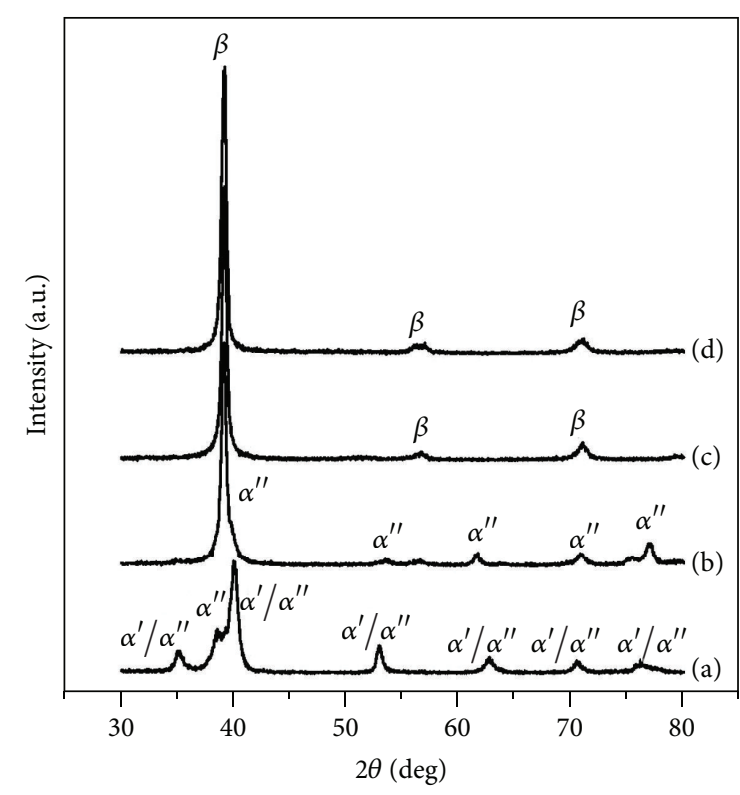

FIgURE 3: XRD patterns of the Ti-xMo alloys.

TABLE 2: Corrosion potentials $\left(E_{\text {corr }}\right)$, corrosion current densities $\left(I_{\text {corr }}\right)$, and passivation current densities $\left(I_{\text {pass }}\right)$ determined from the polarization curves.

\begin{tabular}{lccc}
\hline Sample & $E_{\text {corr }}(\mathrm{mV} / \mathrm{SCE})$ & $I_{\text {corr }}\left(\mu \mathrm{A} / \mathrm{cm}^{2}\right)$ & $I_{\text {pass }}\left(\mu \mathrm{A} / \mathrm{cm}^{2}\right)$ \\
\hline CP Ti & -320 & 1.775 & 3.77 \\
Ti-3Mo & -460 & 0.524 & 1.78 \\
Ti-7Mo & -400 & 0.503 & 1.88 \\
Ti-10Mo & -380 & 0.385 & 2.18 \\
Ti-15Mo & -390 & 0.358 & 2.22 \\
\hline
\end{tabular}

despite the fact that the specimens were prepared using the same procedure. The corrosion potentials $\left(E_{\text {corr }}\right)$, corrosion current densities $\left(I_{\text {corr }}\right)$, and passive current densities $\left(I_{\text {pass }}\right)$ for the alloys, as obtained from their polarization curves, are summarized in Table 2 . The corrosion densities $\left(I_{\text {corr }}\right)$ were obtained from the polarization curves using the Tafel extrapolation method and ranged from 0.358 to $0.524 \mu \mathrm{A} / \mathrm{cm}^{2}$ for the Ti-Mo alloys. The passive current densities $\left(I_{\text {pass }}\right)$ were in the range of $1.78-2.22 \mu \mathrm{A} / \mathrm{cm}^{2}$ for the Ti-Mo alloys, compared with a value of $3.77 \mu \mathrm{A} / \mathrm{cm}^{2}$ for the CP Ti. These results suggest that a protective passive film was formed for the TiMo alloys. The potentiodynamic polarization curve of the Ti$7 \mathrm{wt} \%$ Mo exhibited stable passivation behavior throughout the entire range of potentials. These results indicate that the addition of Mo to pure Ti does not appear to modify the protection characteristics of its spontaneous oxides [18].

3.3. Electrochemical Impedance Spectroscopy (EIS) of Ti-Mo Alloys. Electrochemical impedance analysis between $10 \mathrm{mHz}$ and $10^{5} \mathrm{~Hz}$ with an amplitude of $10 \mathrm{mV}$ at an applied potential was performed for the surfaces of the Ti-Mo alloy during immersion to investigate the electrode/electrolyte interfaces and the processes that occur on these surfaces. 


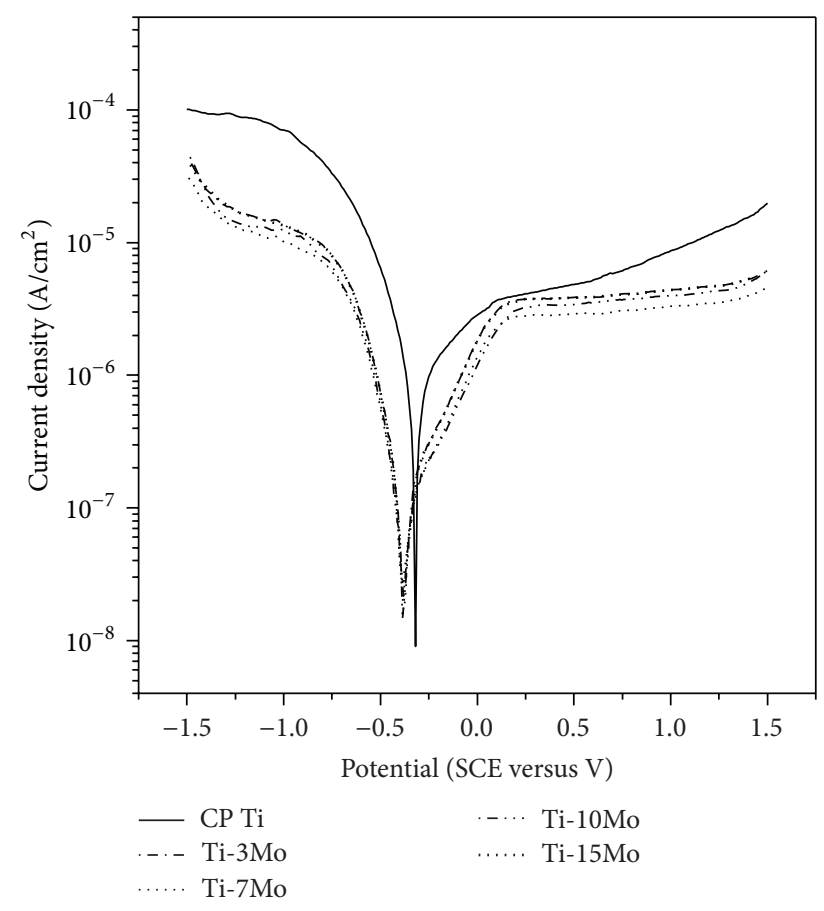

FIgure 4: Potentiodynamic polarization curves of the Ti-Mo alloys in the SBF solution at $37^{\circ} \mathrm{C}$.

Figure 5 presents the Bode magnitude and phase plots for the Ti-Mo alloys. The Bode magnitude plots are similar for all alloys; these plots are characterized by two distinct regions. In the high-frequency range $\left(10^{3}-10^{5} \mathrm{~Hz}\right)$, there is a flat portion (slope $\approx 0$ ) that is associated with the response of the electrolyte resistance. In the broad low- and moderatefrequency ranges, the impedance spectra exhibit linear slopes of approximately -1 , which is the characteristic response associated with the capacitive behavior of a passive film [1921].

For all alloys, two distinct regions characterize the Bode phase plots. In the high-frequency range (over $1 \mathrm{kHz}$ ), the plots exhibit a constant impedance modulus that corresponds to a phase angle near zero degrees. The fact that the phase angle drops to near zero degrees in this high-frequency range indicates that the impedance is dominated by the solution resistance and by the surface-film resistance for the high- and low-frequency cases, respectively. In the highfrequency region, it seems that the phase angle drops to near $0^{\circ}$ along with the response of the electrolyte resistance. In the moderate-frequency region, the phase angle remains near $80^{\circ}$ over a wide frequency range, indicating the presence of a typical passive film on the surface and a near-capacitive response of the passive film [20]. In the low-frequency region, the phase angle decreases to a lower value because of the contribution of the passive-film resistance. In the lowand moderate-frequency ranges below $1 \mathrm{kHz}$, the plots of the impedance modulus versus the frequency exhibit linear slopes. This is the characteristic response associated with the capacitive behavior of a passive film [22, 23].
TABLE 3: Electrical parameters obtained from the EIS data.

\begin{tabular}{lcccc}
\hline Sample & $R_{s}\left(\Omega \mathrm{cm}^{2}\right)$ & $\mathrm{CPE}\left(\mu \mathrm{F} / \mathrm{cm}^{2} \mathrm{~s}^{n}\right)$ & $n$ & $R_{p}\left(\mathrm{M} \Omega \mathrm{cm}^{2}\right)$ \\
\hline Ti-3Mo & 16.23 & 16.11 & 0.9307 & 1.109 \\
Ti-7Mo & 20.57 & 18.29 & 0.9319 & 1.103 \\
Ti-10Mo & 15.38 & 22.52 & 0.9247 & 1.288 \\
Ti-15Mo & 17 & 24.98 & 0.904 & 1.101 \\
\hline
\end{tabular}

To obtain the electrochemical parameters by fitting the experimental EIS results, the equivalent circuit shown in Figure 6 was used for the alloys. Here, $R_{s}$ denotes the solution resistance, $R_{p}$ represents the polarization resistance, and CPE is the constant phase element. The physical model for this equivalent circuit corresponds to the presence of a single layer with both resistance and capacitance on a metal surface. By analyzing the data presented in Table 3, the following conclusions were derived. The values of $n$ were very close to one $(n>0.9)$ for all alloys, indicating a near-capacitive behavior of the passive films formed on the Ti-Mo alloys. The corrosion resistance of the Ti-Mo alloys increased as the Mo content increased.

3.4. Metal-Ion Release of Ti-Mo Alloys. Table 4 presents the concentrations of metal ions released into the SBF solution and the $0.1 \%$ lactic acid over a period of 30 days. In the SBF solution, the elution of $\mathrm{Ti}$ and Mo ions was below the detection limit of $0.01 \mu \mathrm{g} / \mathrm{mL}$, regardless of the alloy composition. By contrast, in the 0.1 lactic acid, Ti-ion release was detected in the range from 0.04 to $0.11 \mu \mathrm{g} / \mathrm{mL}$, depending on the Mo content of the alloy. Moreover, the Ti-ion release from the Ti-7 wt\% Mo alloy was slightly lower than that of conventional Ti-Mo alloys. This result indicates that the corrosion resistance of the Ti alloy with $7 \mathrm{wt} \%$ Mo was slightly better than the corrosion resistance of conventional Ti-Mo alloys, consistent with the results of the electrochemical tests.

3.5. Biocompatibility of Ti-Mo Alloys. The MTT assay was used to determine mitochondrial activity of the cultured osteoblasts on the surface of $\mathrm{CP} \mathrm{Ti}$ and $\mathrm{Ti}-\mathrm{Mo}$ alloys. Figure 7(a) shows the proliferation behavior in MC3T3-E1 cell adhesion after 1 day and 3 days during cell culturing. A sharp difference in the viability of MC3T3-E1 cells was scarcely found in all samples. It seems that the initial cell attachment was not affected by the alloy chemistry. After 3 days, proliferation in cell adhesion slightly increased compared to that of 1 day. Figure 7(b) shows the absorbance obtained from cells adhered to the surface at 3 days. The proliferation and absorbance of the cell showed rather high values for Ti-7 wt $\%$ Mo alloy.

\section{Conclusion}

The elastic modulus, electrochemical properties, and microstructures of homogenization-treated binary Ti-Mo alloys with Mo contents ranging from 3 to $15 \mathrm{wt} \%$ were investigated. The elastic modulus decreased when the Mo content increased up to $7 \%$ and then increased as the 
TABLE 4: Concentrations of metal ions released into two different solutions after various durations at $37^{\circ} \mathrm{C}$.

\begin{tabular}{|c|c|c|c|c|c|c|c|c|c|}
\hline \multirow{2}{*}{ Solution } & \multirow{2}{*}{ Days } & \multicolumn{8}{|c|}{ Metal-ion contents released from Ti-Mo alloys $(0.01 \mu \mathrm{g} / \mathrm{mL})$} \\
\hline & & \multicolumn{2}{|c|}{ Ti-3Mo } & \multicolumn{2}{|c|}{$\mathrm{Ti}-7 \mathrm{Mo}$} & \multicolumn{2}{|c|}{ Ti-10Mo } & \multicolumn{2}{|c|}{ Ti-15Mo } \\
\hline \multirow{2}{*}{ SBF solution } & \multirow{2}{*}{$10-30$} & \multicolumn{2}{|c|}{$<0.01$} & \multicolumn{2}{|c|}{$<0.01$} & \multicolumn{2}{|c|}{$<0.01$} & \multicolumn{2}{|c|}{$<0.01$} \\
\hline & & $\mathrm{Ti}$ & Mo & $\mathrm{Ti}$ & Mo & $\mathrm{Ti}$ & Mo & $\mathrm{Ti}$ & Mo \\
\hline \multirow{5}{*}{$0.1 \%$ lactic acid } & 10 & 0.11 & 0.01 & 0.08 & $<0.01$ & 0.09 & $<0.01$ & 0.11 & 0.01 \\
\hline & 15 & 0.06 & $<0.01$ & 0.07 & $<0.01$ & 0.06 & $<0.01$ & 0.09 & $<0.01$ \\
\hline & 20 & 0.05 & $<0.01$ & 0.06 & $<0.01$ & 0.06 & $<0.01$ & 0.07 & $<0.01$ \\
\hline & 25 & 0.04 & $<0.01$ & 0.04 & $<0.01$ & 0.05 & $<0.01$ & 0.07 & $<0.01$ \\
\hline & 30 & 0.04 & $<0.01$ & 0.04 & $<0.01$ & 0.04 & $<0.01$ & 0.05 & $<0.01$ \\
\hline
\end{tabular}

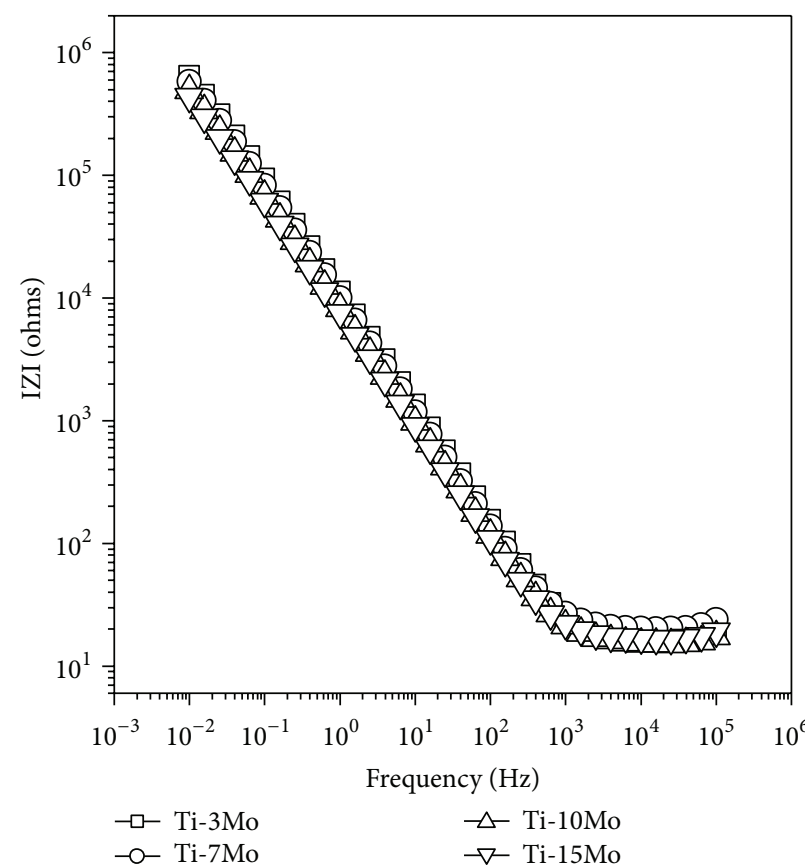

(a) Bode plot

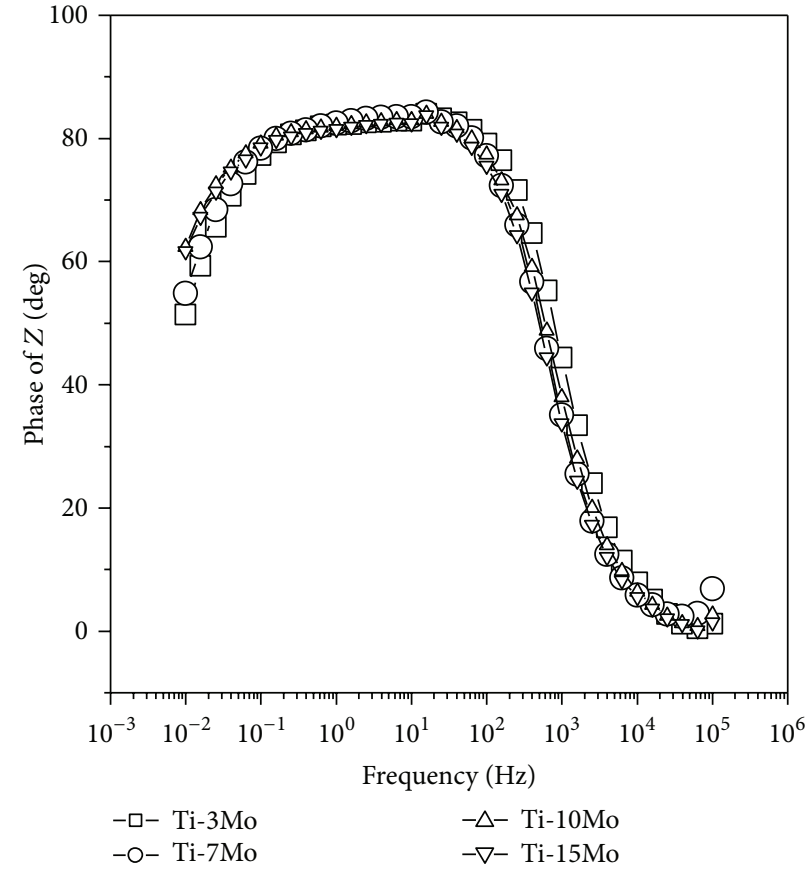

(b) Bode phase plot

FIgURE 5: Bode spectra for the Ti-Mo alloys: (a) Bode magnitude plots and (b) Bode phase plots.

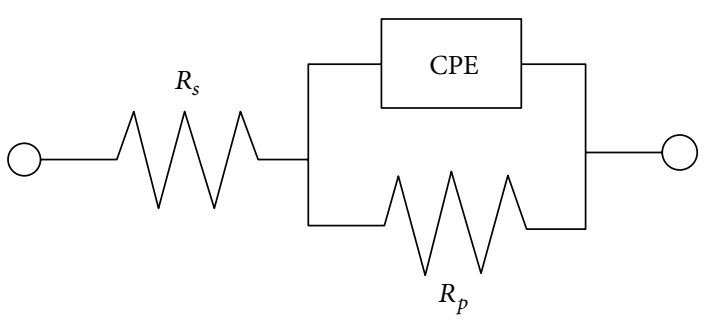

FIGURE 6: Equivalent circuit used to fit the EIS data.

Mo content was further increased to $15 \%$. Microstructure morphology of the Ti-7 wt\% Mo alloy showed only a fine acicular martensitic structure of the orthorhombic $\left(\alpha^{\prime \prime}\right)$ phase. An EIS data analysis confirmed that the polarization resistance of the Ti-Mo alloys increased as the Mo content was increased. The corrosion resistance of the Ti-Mo alloys increased with increasing Mo content. The Ti-7Mo alloy exhibited a relatively low elastic modulus and low metal-ion release. Near-capacitive behavior of the passive films was observed in the electrochemical impedance analysis, which reflected the corrosion resistance of the Ti-Mo alloys. MC3T3-E1 cell proliferation on Ti-7 wt\% Mo was rather 


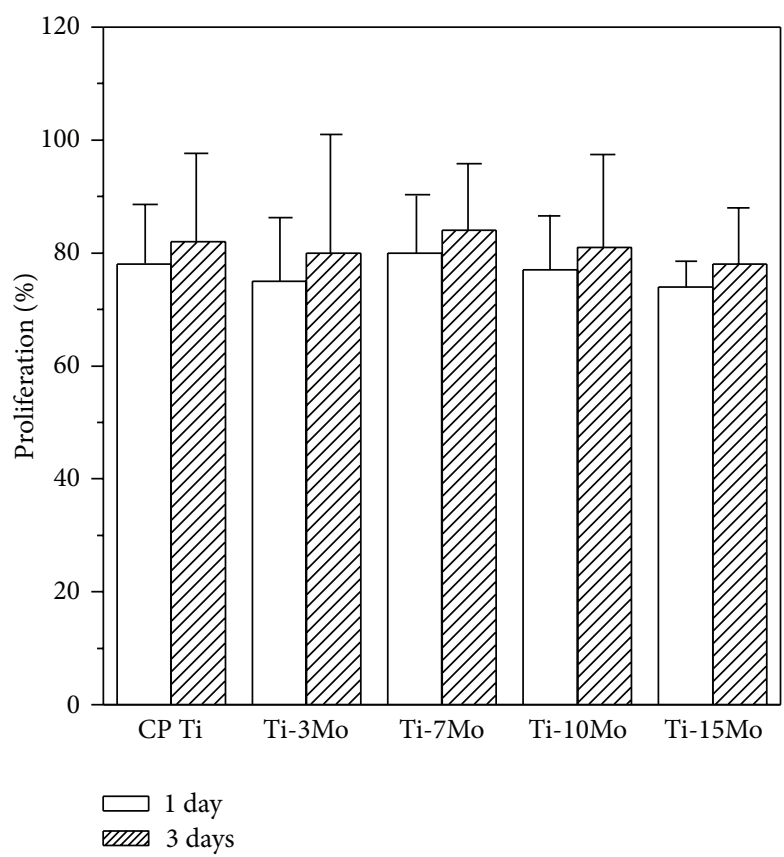

(a)

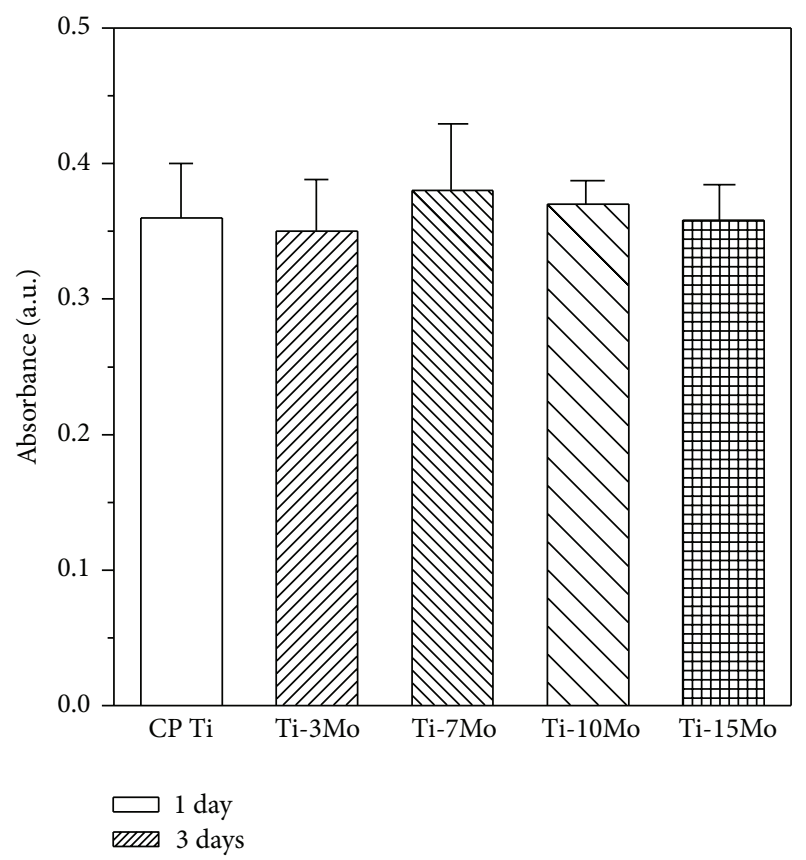

(b)

FIGURE 7: Cell proliferation tested with MC3T3-E1 osteoblasts after 1 day and 3 days of incubation.

active than other Ti-Mo alloys and CP Ti. The low elastic modulus and good biocompatibility suggest that $\mathrm{Ti}-7 \mathrm{Mo}$ alloy is promising metallic biomaterials.

\section{Conflict of Interests}

The authors declare that there is no conflict of interests regarding the publication of this paper.

\section{Acknowledgment}

This study was supported by research fund from Chosun University, 2013.

\section{References}

[1] A. Schroeder, F. Sutter, and G. Krekeler, Oral Implantology, Thieme Medical Publishers, New York, NY, USA, 1991.

[2] S. Kumar, T. S. N. Sankara Narayanan, and S. Saravana Kumar, "Influence of fluoride ion on the electrochemical behaviour of $\beta$-Ti alloy for dental implant application," Corrosion Science, vol. 52, no. 5, pp. 1721-1727, 2010.

[3] M. A. Khan, R. L. Williams, and D. F. Williams, "The corrosion behaviour of $\mathrm{Ti}-6 \mathrm{Al}-4 \mathrm{~V}, \mathrm{Ti}-6 \mathrm{Al}-7 \mathrm{Nb}$ and $\mathrm{Ti}-13 \mathrm{Nb}-13 \mathrm{Zr}$ in protein solutions," Biomaterials, vol. 20, no. 7, pp. 631-637, 1999.

[4] M. Long and H. J. Rack, "Titanium alloys in total joint replacement-a materials science perspective," Biomaterials, vol. 19, no. 18, pp. 1621-1639, 1998.

[5] F. Xie, X. He, S. Cao, M. Mei, and X. Qu, "Influence of pore characteristics on microstructure, mechanical properties and corrosion resistance of selective laser sintered porous Ti-Mo alloys for biomedical applications," Electrochimica Acta, vol.105, pp. 121-129, 2013.

[6] M. Niinomi, "Fatigue performance and cyto-toxicity of low rigidity titanium alloy, Ti-29Nb-13Ta-4.6Zr," Biomaterials, vol. 24, no. 16, pp. 2673-2683, 2003.

[7] H. Liu, M. Niinomi, M. Nakai, J. Hieda, and K. Cho, "Changeable Young's modulus with large elongation-to-failure in $\beta$ type titanium alloys for spinal fixation applications," Scripta Materialia, vol. 82, pp. 29-32, 2014.

[8] M. Geetha, A. K. Singh, R. Asokamani, and A. K. Gogia, "Ti based biomaterials, the ultimate choice for orthopaedic implants-a review," Progress in Materials Science, vol. 54, no. 3, pp. 397-425, 2009.

[9] M. Niinomi, D. Kuroda, K.-I. Fukunaga et al., "Corrosion wear fracture of new $\beta$ type biomedical titanium alloys," Materials Science and Engineering A, vol. 263, no. 2, pp. 193-199, 1999.

[10] M. F. Ijaz, H. Y. Kim, H. Hosoda, and S. Miyazaki, "Superelastic properties of biomedical (Ti-Zr)-Mo-Sn alloys," Materials Science and Engineering: $C$, vol. 48, pp. 11-20, 2015.

[11] M. Popa, J. M. Calderon Moreno, C. Vasilescu et al., "Structural analysis, electrochemical behavior, and biocompatibility of novel quaternary titanium alloy with near $\beta$ structure," Metallurgical and Materials Transactions A: Physical Metallurgy and Materials Science, vol. 45, no. 7, pp. 3130-3143, 2014.

[12] S. E. Kim, H. W. Jeong, Y. T. Hyun et al., "Elastic modulus and in vitro biocompatibility of Ti-xNb and Ti-xTa alloys," Metals and Materials International, vol. 13, no. 2, pp. 145-149, 2007.

[13] H.-C. Hsu, S.-C. Wu, S.-K. Hsu, C.-T. Li, and W.-F. Ho, "Effects of chromium addition on structure and mechanical properties of Ti-5Mo alloy," Materials and Design, vol. 65, pp. 700-706, 2015.

[14] Y. Li and K. A. Khor, "Mechanical properties of the plasmasprayed $\mathrm{Al}_{2} \mathrm{O}_{3} / \mathrm{ZrSiO}_{4}$ coatings," Surface and Coatings Technology, vol. 150, no. 2-3, pp. 143-150, 2002. 
[15] W. F. Ho, C. P. Ju, and J. H. Chern Lin, "Structure and properties of cast binary Ti-Mo alloys," Biomaterials, vol. 20, no. 22, pp. 2115-2122, 1999.

[16] M. Petrzhik, "Dynamics of martensitic structure at TiNb-based quenched alloys under heating and loading," Journal of Physics: Conference Series, vol. 438, Article ID 012020, pp. 1-5, 2013.

[17] H.-K. Kim and J.-W. Jang, "Electrochemical corrosion behavior and MG-63 osteoblast-like cell response of surface-treated titanium," Metals and Materials International, vol. 10, no. 5, pp. 439-446, 2004.

[18] N. T. C. Oliveira and A. C. Guastaldi, "Electrochemical behavior of Ti-Mo alloys applied as biomaterial," Corrosion Science, vol. 50, no. 4, pp. 938-945, 2008.

[19] A. W. E. Hodgson, Y. Mueller, D. C. Forster, and S. Virtanen, "Electrochemical characterisation of passive films on Ti alloys under simulated biological conditions," Electrochimica Acta, vol. 47, no. 12, pp. 1913-1923, 2002.

[20] F. Rosalbino, D. MacCiò, G. Scavino, and A. Saccone, "In vitro corrosion behaviour of $\mathrm{Ti}-\mathrm{Nb}$-Sn shape memory alloys in Ringer's physiological solution," Journal of Materials Science: Materials in Medicine, vol. 23, no. 4, pp. 865-871, 2012.

[21] Y. Bai, S. J. Li, F. Prima, Y. L. Hao, and R. Yang, "Electrochemical corrosion behavior of $\mathrm{Ti}-24 \mathrm{Nb}-4 \mathrm{Zr}-8 \mathrm{Sn}$ alloy in a simulated physiological environment," Applied Surface Science, vol. 258, no. 8, pp. 4035-4040, 2012.

[22] J. E. G. González and J. C. Mirza-Rosca, "Study of the corrosion behavior of titanium and some of its alloys for biomedical and dental implant applications," Journal of Electroanalytical Chemistry, vol. 471, no. 2, pp. 109-115, 1999.

[23] C. Vasilescu, P. Drob, E. Vasilescu, P. Osiceanu, S. L. Drob, and M. V. Popa, "Electrochemical and corrosion behaviour of a new titanium base alloy in simulated human electrolytes," International Journal of Electrochemical Science, vol. 8, no. 8, pp. 10733-10745, 2013. 

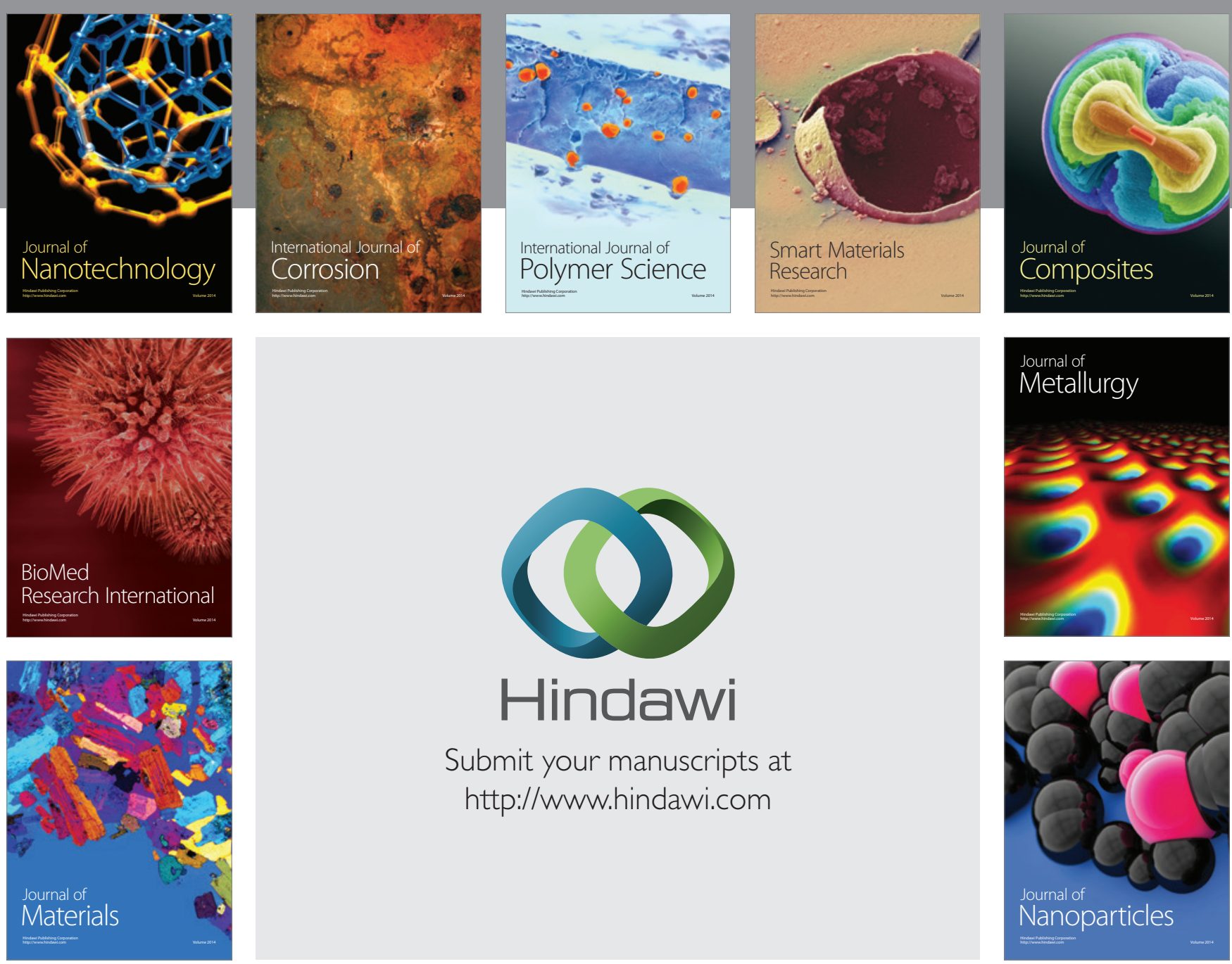

Submit your manuscripts at http://www.hindawi.com
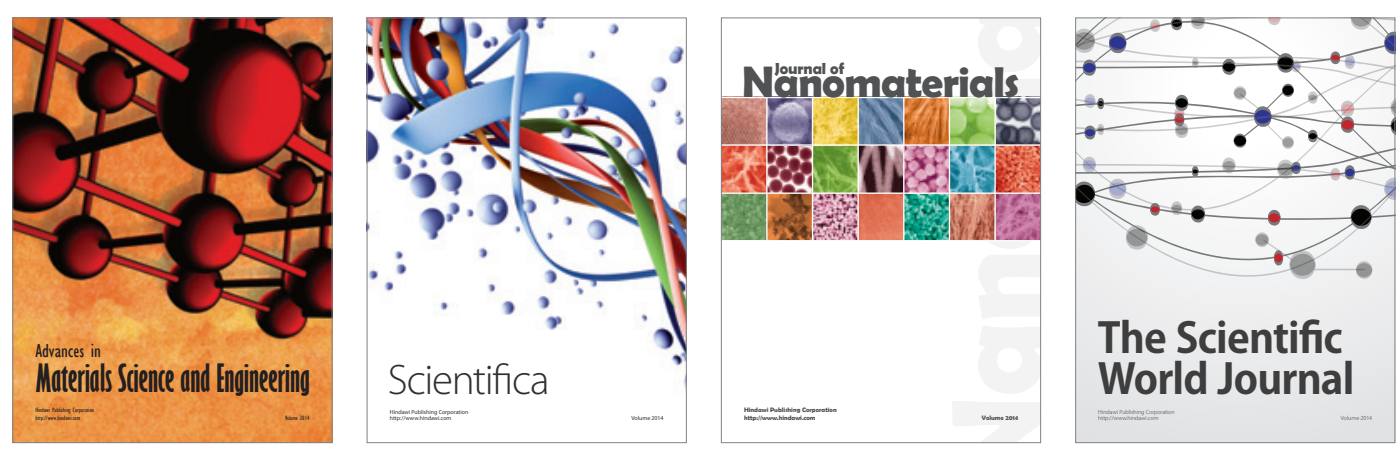

\section{The Scientific World Journal}
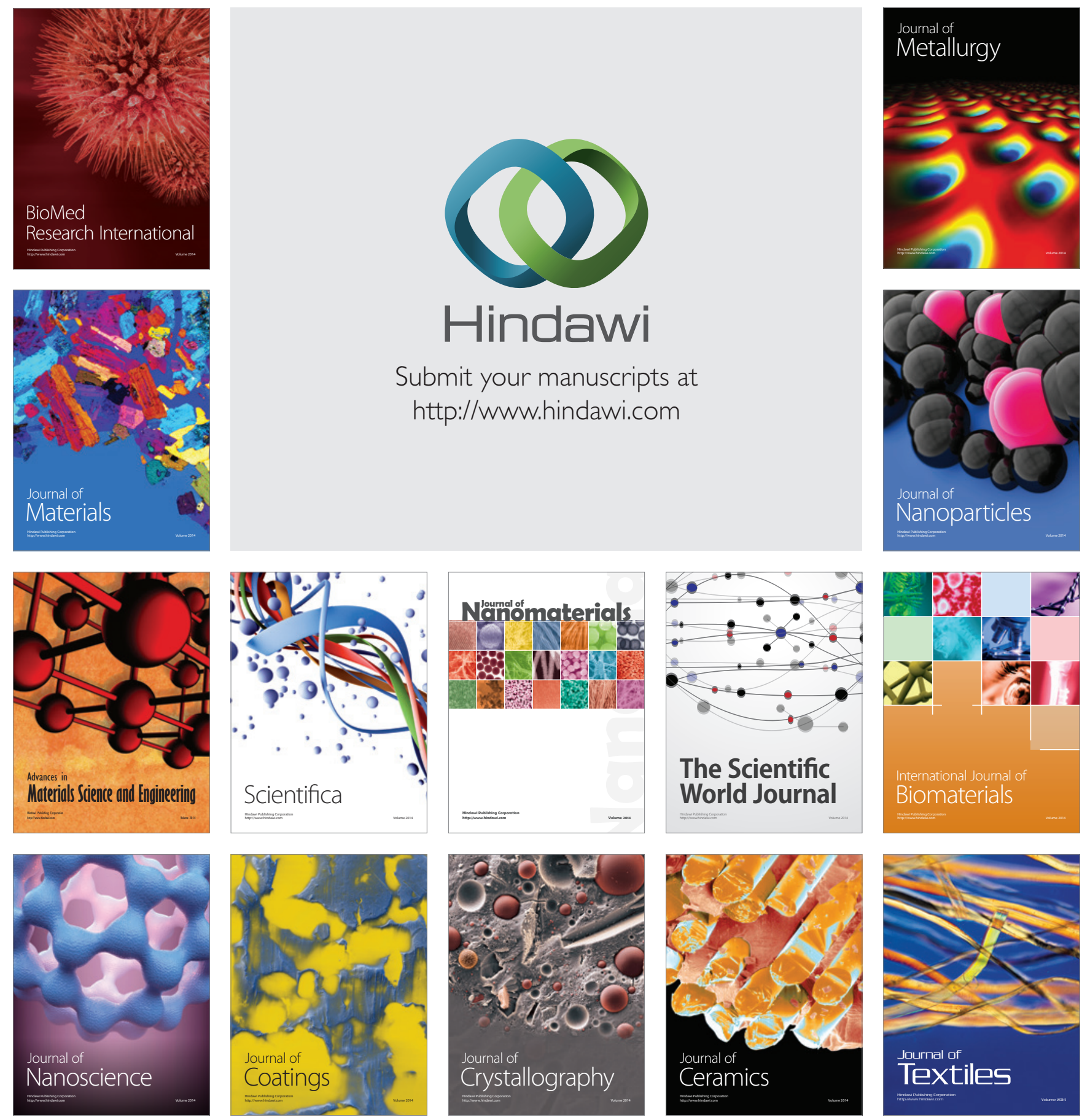